\title{
Economic Individualism and Job Engagement: Examining the Roles of Work Motivation and Growth Need Strength
}

\author{
Jinkyo Shin ${ }^{1}$, Nicholas A. Moon ${ }^{2} \mathbb{(}$, Jesse Caylor ${ }^{2}$, Patrick D. Converse ${ }^{2}$, Okja Park ${ }^{3}$ and Kyunghwan Yeo ${ }^{4, *}$ \\ 1 College of Business, Keimyung University, Daegu 42601, Korea; sdata88@kmu.ac.kr \\ 2 School of Psychology, Florida Institute of Technology, 150 W. University Blvd., Melbourne, FL 32901, USA; \\ nmoon2016@my.fit.edu (N.A.M.); jcaylor2016@my.fit.edu (J.C.); pconvers@fit.edu (P.D.C.) \\ 3 School of Psychology, Sunmoon University, Asan-si 31460, Korea; ojhappy3@sunmoon.ac.kr \\ 4 HR Institute for University-Industry Cooperation, Keimyung University, Daegu 42601, Korea \\ * Correspondence: ykh0544@kmu.ac.kr
}

check for updates

Citation: Shin, J.; Moon, N.A.; Caylor, J.; Converse, P.D.; Park, O.; Yeo, K. Economic Individualism and Job Engagement: Examining the Roles of Work Motivation and Growth Need Strength. Sustainability 2022, 14, 591. https://doi.org/10.3390/su14020591

Academic Editor: Ermanno C. Tortia

Received: 4 December 2021

Accepted: 31 December 2021

Published: 6 January 2022

Publisher's Note: MDPI stays neutral with regard to jurisdictional claims in published maps and institutional affiliations.

Copyright: (c) 2022 by the authors. Licensee MDPI, Basel, Switzerland. This article is an open access article distributed under the terms and conditions of the Creative Commons Attribution (CC BY) license (https:/ / creativecommons.org/licenses/by/ $4.0 /)$.

\begin{abstract}
Economic individualism-involving a belief that the individual should be in control of his/her own economic decisions and an increased emphasis on competition and achievement-is becoming more prominent in several areas of the world, but little is known about the implications of this characteristic for employee attitudes and behavior. Our study investigated the impact of economic individualism on job engagement. More specifically, the research developed and examined a model involving work motivation as a mediator and growth need strength as a moderator. Employees ( $N=235,58.3 \%$ male, $33.6 \% 20-29$ years old, $53.2 \%$ with a bachelor's degree) from several companies in South Korea completed survey measures of economic individualism, job engagement, work motivation, and growth need strength. Findings supported work motivation as a mediator and indicated that the indirect effect through work motivation was significant at high levels of growth need strength although not at low levels. These findings provide new insights regarding the individuallevel engagement implications of economic individualism and when and why these implications hold, as prior research on economic individualism has focused on the organizational and societal levels.
\end{abstract}

Keywords: economic individualism; job engagement; work motivation; growth need strength

\section{Introduction}

An individual's values can have an important influence on behavior, emotional responses, and decision-making processes [1,2]. Individual-level values may originate from many sources (e.g., personal experience, religious upbringing) [3]. However, in many cases, individual values reflect the overall cultural and economic conditions of the area in which the individual functions [4]. A major example of this can be seen in East Asian countries (e.g., Japan, South Korea, Taiwan, and Singapore). During the twentieth century, the economy of these countries developed rapidly. Over this period of rapid growth, a corresponding sense of economic individualism emerged [5], involving a belief that the individual should be in control of his or her own economic decisions and an increased emphasis on competition and achievement [6].

Although economic individualism is becoming more prominent, little is known about the implications of this value for employee attitudes and behavior. In fact, economic individualism has been explored at the societal and organizational levels, but very little research has investigated this value at the individual level. For example, in terms of the societal level, much of the research on economic individualism has focused on poverty and welfare at the national level $[7,8]$. At the organizational level, organizations within China have shifted from more collectivist principles to more individualistic economic views over the past century [9]. Dowling and Pfeffer [10] suggest that this transition is essential for organizations looking to retain organizational legitimacy. An organization is said to have legitimacy if its values align with the values of the larger society within which it operates. 
The importance of organizational legitimacy has been seen in the way that it influences the decisions of consumers and, ultimately, organizational effectiveness [11]. In contrast, little research has examined the ways in which economic individualism may influence employee attitudes and behaviors. Investigating the individual level may be useful because prior work suggests that individualism can be studied at multiple levels of analysis [12] but findings at one level may not generalize to other levels.

In summary, (a) economic individualism is increasingly prominent, (b) prior research has examined this value at the societal and organizational levels, but (c) little is known about the individual-level implications of this characteristic, though conceptual analysis (discussed later) suggests there may be links to employee attitudes and behaviors. Thus, the present study seeks to address this gap and further the field's understanding of economic individualism by examining this characteristic at the individual level, focusing on connections with job engagement. This research focuses on job engagement because it is a major concern for many organizations given it has links to several important individual and organizational outcomes (e.g., organizational commitment, turnover intentions, performance) $[13,14]$. More specifically, this research develops and examines a model in which work motivation mediates the relationship between economic individualism and job engagement and growth need strength moderates the relationship between economic individualism and work motivation. Further advancing this area of research in this way may contribute to both theory and practice. By examining when and why economic individualism predicts employee attitudes and behavior, this study provides a deeper level of understanding of the construct as well as its importance in determining individual outcomes that can inform theoretical models and practical interventions focusing on engagement issues. The following sections discuss (a) the conceptualization of economic individualism and job engagement, (b) the hypothesized linkage between these variables, (c) the potential role of work motivation, and (d) the potential role of growth need strength.

For this purpose, regression analysis and the PROCESS macro suggested by Hayes [15] were used to examine the relationships between major variables, the moderating effect of growth need strength, the mediating effect of motivation, and the moderated mediating effect of growth need strength.

\section{Literature Review and Hypothesis Development}

\subsection{Literature Review}

\subsubsection{Economic Individualism}

Individualism is a value that has been described as "a focus on rights above duties, a concern for oneself and immediate family, and emphasis on personal autonomy and self-fulfillment" [12]. Thus, individualism tends to involve prioritizing one's goals and wellbeing, promoting one's positive sense of self, and independence from others. For example, Gorodnichenko and Roland [16] noted that cultures with highly individualistic values tend to provide social status rewards and monetary incentives for personal achievement, which leads to higher rates of economic growth and innovation. However, Chou [17] noted that definitions of individualism differ somewhat and suggested that there are four general definitions of this value. These definitions are concerned with (a) the sanctity of self, (b) the interest of the individual, (c) being self-reliant, and (d) work ethic and equal opportunity. These four definitions can be grouped into two types of individualism: social individualism and economic individualism. Social individualism is defined as a philosophy that motivates one to subscribe to the idea of self-centeredness, privacy, and indifference to the outside social environment [17]. Economic individualism is defined as a belief that the individual rather than the government should be in control of one's economic decisions, with an increased emphasis on competition, achievement, and pursuit of happiness [6]. The current study is concerned with economic individualism. This viewpoint emphasizes the free market mechanism, sanctity of private property, and economic deregulation [18]. Thus, an individual who scores high on economic individualism likely prefers minimum government intervention, economic individuality, and economic self-reliance. 
Two additional issues related to conceptualization should be noted. These issues relate to previous work on individualism in general rather than economic individualism in particular, but they have implications for the conceptualization of economic individualism. First, although some research has focused on differences in individualism between countries, most studies have examined individual differences in this variable [2]. This supports investigating economic individualism at the individual level. Second, some researchers have viewed individualism and collectivism as a single bipolar dimension, whereas others have viewed them as distinct constructs $[12,19]$. This issue does not appear to have been fully resolved, but some researchers [19] have argued that much of the conceptual and empirical work at the individual level has supported the multidimensional conceptualization. This suggests that individuals who are low on economic individualism may not necessarily endorse a collectivism view of economic issues. Given this, the present research focuses conceptually and empirically on economic individualism and its potential implications, rather than on contrasting economic individualism with economic collectivism.

The majority of research on economic individualism has focused on poverty and welfare at the national level $[18,20]$. Economic individualism postulates that people are motivated by financial interests, each individual is responsible for his/her own welfare, and economic success is the result of hard work [20,21]. From this perspective, poverty is considered a consequence of one's lack of work or cultural deficiency. This implies that an individual should not shift responsibility for his/her failure to others [14,20,22]. To elaborate, multiple attributions for poverty exist and can be categorized into individualistic, structural, and fatalistic [7,22,23]. The individual explanation emphasizes individual deficits as the main cause of poverty; the structural explanation focuses on deficiencies at the social levels of the economy; and the fatalistic explanation attributes poverty to factors that individuals cannot control [24]. Among these three, the individual explanation is conceptually related to economic individualism.

\subsubsection{Job Engagement}

To date, there is not a universally accepted definition for the term job engagement. Therefore, this research draws from Schaufeli et al.'s [25] definition: "a positive, fulfilling, work-related state of mind that is characterized by vigor, dedication, and absorption" (p. 76). Vigor refers to high levels of energy and resilience in one's work. Dedication refers to experiencing enthusiasm, inspiration, pride, and challenge while working. Absorption is characterized by concentration on and commitment to the work. Based on this, job engagement is generally defined as fundamentally a motivational concept that represents the active allocation of personal resources toward the tasks associated with a work role [26].

Engagement is a major concern for many organizations because it has important implications for individual and organizational outcomes. For instance, employees with high levels of engagement generally concentrate on physical, cognitive, and emotional energy during the pursuit of goals [27], whereas employees who are disengaged in their work are robotic, passive, and detached [28]. Employee engagement has also been associated with higher levels of organizational commitment and lower turnover intentions [13]. Furthermore, engaged employees receive higher ratings for in-role and extra-role performance from colleagues [29] and supervisors [14].

Most research conducted on job engagement has centered on its potential antecedents [30-33]. Christian and colleagues' [26] meta-analysis supported job characteristics as an antecedent of job engagement. More specifically, characteristics of the job and organization such as job autonomy [34], structural empowerment [31], colleague support [35], person-job fit, and resource availability [36] were suggested as antecedents of job engagement. However, research has yet to examine the role of economic individualism in predicting job engagement. 


\subsection{Hypothesis Development}

\subsubsection{Economic Individualism and Job Engagement}

In contrast to prior research's focus on national-level poverty, little research has examined the effects of economic individualism for individual attitudes and behavior. However, based on the conceptualization of this characteristic, it may also have important implications at the individual level. We draw from the Value-Attitude-Behavior (VAB) model $[20,37]$ to conceptualize these potential implications. In general, the VAB model suggests that values influence attitudes, which in turn influence behaviors. This theory is based on a cognitive hierarchy model involving the notion that the values pursued by a person determine their attitudes and behaviors, and thus that human behavior is based on one's values. As discussed by Homer and Kahle [20], values are conceptualized as a type of social cognition that assists individuals in adapting to their environments. Values are seen as the most abstract of the social cognitions and thus function as prototypes that influence relevant attitudes and behaviors. Therefore, this theoretical framework indicates that abstract values influence midrange attitudes, which then influence specific behaviors. In the current context, this suggests that economic individualism (a value) may have implications for job engagement (an attitude).

In particular, economic individualism may tend to have positive links to work-related attitudes and behaviors under conditions in which individual efforts are supported and rewarded. That is, when provided the opportunity to strive toward individual achievements and associated rewards, those high on economic individualism may tend to thrive because this is consistent with their beliefs related to individual economic control, achievement, and self-reliance. In contrast, those low on economic individualism may have less positive experiences and outcomes in these types of organizational conditions because they do not match their underlying economic beliefs. Note, however, that the opposite may hold under other conditions. For instance, an organizational system that provides the same rewards regardless of effort or performance may undermine the experiences and work motivation of those high on economic individualism. Thus, economic individualism may not be a universally advantageous characteristic in organizations. However, the current research examines contexts in which individual striving is supported and rewarded, and thus we focus on the potential for positive implications associated with economic individualism.

Specifically, this research examines implications for job engagement given its importance in many organizations. Individuals high in economic individualism are likely to regard their rewards as the fruits of their own hard work. Therefore, they are likely to be more engaged at their job in order to experience economic gains, as economic individualism contends that each individual should get ahead on his/her own through hard work [8]. We propose that this belief drives people to work hard and invest themselves more fully into their job.

\section{Hypothesis 1 (H1). Economic individualism is positively related to job engagement.}

\subsubsection{Economic Individualism, Work Motivation and Job Engagement}

Motivation is an "unobservable force that directs, energizes, and sustains behavior over time and across changing circumstances" [38]. A prominent approach to motivation in achievement-related contexts is self-determination theory (SDT), which proposes that distinct types of motivation in these contexts have differing antecedents and consequences [39]. In particular, SDT emphasizes two types of motivation: intrinsic and extrinsic. Intrinsic motivation involves "activities for which the motivation lies in the behavior itself. When intrinsically motivated, it is the spontaneous experiences of interest and enjoyment entailed in the activity that supply the 'rewards'" [39]. Inherent to this definition, intrinsic motivation is considered a type of autonomous motivation, meaning it occurs independent of other influences. Extrinsic motivation involves "doing something because it leads to a separable outcome" [40]. Furthermore, Deci and Ryan [40] explain that extrinsic motivation tends to be more controlled. Given the conceptualizations of economic individualism and 
extrinsic motivation, there is likely to be a positive relationship between these variables. From the perspective of economic individualism, external rewards (e.g., wealth, recognition, power) are the desired outcome of hard work [7]. In addition, those with values strongly anchored in beliefs of economic individualism are likely to find compensation systems to be motivating [41]. Therefore, the perspective of economic individualism clearly involves a tendency to be motivated by extrinsic rewards. Furthermore, economic individualism may also be positively related to intrinsic motivation. Those higher in economic individualism may feel a greater sense of control over their lives, as they believe the individual rather than institutions should be in control of the pursuit of advancement and happiness. This greater sense of autonomy may then foster greater intrinsic motivation. This suggests that higher economic individualism may be associated with higher levels of both extrinsic and intrinsic motivation.

Based on previous research, both extrinsic and intrinsic motivation are positively related to employee engagement [42]. According to Van den Broeck et al. [43], individuals must demonstrate a basic level of autonomy to be engaged within their organization. The authors noted that individuals who demonstrate an increased need for achievement will demonstrate higher attention and engagement and, therefore, will be more likely to receive a financial bonus. Overall, this suggests that work motivation is positively related to job engagement [43]. Taken together, these findings suggest that economic individualism promotes overall work motivation (i.e., extrinsic and intrinsic motivation) and this translates into job engagement.

Hypothesis 2 (H2). Work motivation mediates the relationship between economic individualism and job engagement.

\subsubsection{Economic Individualism, Work Motivation and Growth Need Strength}

Growth need strength (GNS) has been defined as "a measure of an individual's desire to grow and develop within his/her job" [44]. Hackman and Oldham [45] suggest GNS is the desire to obtain growth satisfaction from work. Therefore, GNS can generally be defined as an individual's level of higher-order need for both personal growth and development at work [46]. Hackman and Oldham [45] originally discussed the implications of GNS within the context of job characteristics theory. Job characteristics theory focuses on five core job characteristics (skill variety, task identity, task significance, autonomy, and jobbased feedback) that are thought to influence work motivation and other outcomes $[47,48]$. According to this theory, GNS moderates the relationship between these job characteristics and outcomes. Prior research has supported this notion, demonstrating that GNS moderates the effects of core job dimensions and psychological states on personal and work outcomes [49]. Subsequent studies have also revealed that GNS is an important moderator in the relationship between job characteristics and work attitudes [50]. For example, Zargar et al. [50] found that GNS moderated the relationship between job scope and affective commitment, such that this positive relationship was stronger at higher levels of GNS. However, few studies have investigated GNS's moderating role in the relationship between values (particularly economic individualism) and work motivation.

Given the nature of GNS, we propose that this variable may lead to a stronger positive relationship between economic individualism and work motivation. In the context of job characteristics theory, GNS was proposed as a moderator based on the notion that not everyone will respond the same to more challenging jobs [48] — those with higher GNS will respond more positively because a challenging job matches their higher-order growth need. Extending this logic to the current context, we suggest that not everyone will respond the same (in terms of work motivation) to having a higher level of economic individualism - those with higher GNS will respond more positively (experience greater work motivation) because the beliefs underlying economic individualism match their higher-order growth need. More specifically, high economic individualism combined with high GNS may lead to particularly high levels of work motivation, as these individuals 
believe in individual control of economic pursuits and have a strong need for personal growth. These individuals thus have both beliefs and needs related to individual pursuits, which likely translates into greater motivation in work settings. In contrast, high economic individualism combined with low GNS may not be associated with high work motivation, as these individuals may believe in individual control but they do not have much need for personal growth. Without this need for growth, the economic belief may not translate into work motivation.

Hypothesis 3 (H3). GNS moderates the relationship between economic individualism and work motivation, such that the positive relationship between economic individualism and work motivation is stronger for higher levels of GNS.

In combination, Hypotheses $\mathrm{H} 2$ and $\mathrm{H} 3$ suggest that the indirect effect of economic individualism on job engagement through work motivation may hold only for higher levels of GNS. That is, GNS is suggested to be an important factor influencing the implications of economic individualism. When GNS is high, the relationship between economic individualism and work motivation is proposed to be stronger. Thus, we suggest that the indirect effect through work motivation may hold only when GNS is high.

Hypothesis 4 (H4). The indirect effect of economic individualism on job engagement through work motivation holds only for higher levels of GNS.

\section{Methodology}

\subsection{Participants and Method}

Two hundred and thirty-five employees in South Korean companies were recruited for this study. Within this sample, $58.3 \%$ of participants were male and $41.7 \%$ were female. Participants' age was distributed relatively equally among 20-29 years old (33.6\%), $30-39$ years old $(32.8 \%), 40-49$ years old (23.8\%), and $50-59$ years old (9.8\%). A majority of participants had earned a bachelor's degree $(53.2 \%)$, followed by master's degree or doctoral degree (17.9\%), junior college degree (15.7\%), and high school degree (13.2\%). As for the size of the companies, $44.2 \%$ had less than 100 employees, $2.5 \%$ had more than 100 and less than 300, and 17.9\% had more than 300 and less than 1000 employees. The ranks of employees were employee $39.6 \%$, manager $17.0 \%$, general manager $19.8 \%$, and director $7.2 \%$. By industry, 30.0\% were in the manufacturing industry, $40.0 \%$ in the service industry, and $14.1 \%$ public institutions. White collar was $80.6 \%$, blue collar $6.0 \%$, and others $13.4 \%$. These participants worked in contexts in which individual striving was supported and rewarded. After Korea's IMF crisis in 1997, many Korean companies abolished the existing seniority-oriented salary system and introduced an individual performance-based salary system based on personnel evaluation. As a result, individual performance is reflected in wages and promotions.

Both online and paper questionnaires were used for data collection. It is important to note that this study was part of a larger data collection and thus additional measures were included in the survey, but are outside the scope of the current study. Since this study was conducted in Korean, items unavailable in Korean were translated using the standard translation-back-translation procedure by three professionals in English-Korean translation [51].

\subsection{Measures}

\subsubsection{Job Engagement}

Job engagement was assessed using the Utrecht Work Engagement Scale (UWES) developed by Schaufeli et al. [25]. The items of the UWES are grouped into three subscales that reflect the underlying dimensions of engagement: vigor (six items), dedication (five items), and absorption (six items). All items are rated on a seven-point frequency rating scale ranging from 1 (never) to 7 (always). A sample vigor item is "At my work, I feel 
bursting with energy". A sample dedication item is "I find the work that I do full of meaning and purpose". A sample absorption item is "Time flies when I am working". Some evidence suggests that a one-factor model and a three-factor model of work engagement are equally appropriate [52-54]. In addition, researchers have argued that a one-factor approach is more practically useful [32]. Therefore, all subscales were aggregated to provide an indication of overall job engagement. Previous research has established adequate reliability for the overall job engagement scale with alpha $=0.88$ [22]. In the current study, alpha $=0.92$.

\subsubsection{Economic Individualism}

Economic individualism was assessed with a seven-item measure developed based on the work of Shen and Edward [8] and Hasenfeld and Rafferty [7]. Responses ranged from 1 (strongly disagree) to 7 (strongly agree). Sample items are "If people work hard, they almost always get what they want" and "When people fail at one thing after another, it usually means that they are lazy and lack self-discipline". In the current study, alpha $=0.82$.

\subsubsection{Work Motivation}

Work motivation was assessed with a 14-item measure developed by Van Herpen and colleagues [41], which includes intrinsic motivation (seven items) and extrinsic motivation (seven items). Responses ranged from 1 (strongly disagree) to 7 (strongly agree). A sample item for intrinsic motivation is "My job is worth the effort." A sample item for extrinsic motivation is "I'm satisfied with the way in which my compensation is determined". Based on the previous arguments indicating that the hypothesized relationships should be in the same direction for intrinsic and extrinsic motivation and consistent with previous research [55], an overall work motivation score was calculated. Previous research has established adequate reliability for this measure with alpha $=0.77$ for extrinsic motivation and alpha $=0.84$ for intrinsic motivation [41]. In the current study, alpha $=0.81$.

\subsubsection{Growth Need Strength}

GNS was assessed using Hackman and Oldham's [45] six-item measure. Responses ranged from 1 (strongly disagree) to 7 (strongly agree). A sample item is "I enjoy stimulating and challenging work". Previous research has established adequate reliability for the GNS scale with alpha $=0.88$ [45]. In the current study, alpha $=0.86$.

\subsection{Analysis}

For hypothesis testing, SPSS 25.0 and AMOS 25.0 were used in this study, and the statistical methods used are as follows. First, a frequency analysis was conducted to identify the demographic characteristics of respondents. Second, descriptive statistics such as mean, standard deviation, and correlation were examined to understand the characteristics of each variable. Through this, the levels of job engagement, economic individualism, motivation, and GNS of respondents were identified, and the approximate relationships between variables were identified. Third, we performed Harman's single-factor test to explore common method bias. Fourth, regression analysis was performed to examine the focal relationships. Finally, mediation and the moderated mediating effect of GNS was verified using the SPSS PROCESS macro suggested by Hayes [23].

\section{Results}

Table 1 lists means, standard deviations, correlations, and reliabilities. Before examining the hypotheses, we investigated the potential for common method variance (CMV). First, not all of the correlations between the current variables are notable (e.g., the correlation between economic individualism and GNS is $0.06, \mathrm{~ns})$. This suggests the relationships in this study do not just reflect CMV [56]. Second, we also conducted Harman's singlefactor test where a measurement model is tested with all indicators loading on a single factor. This model had extremely poor fit $\left(\chi^{2} / \mathrm{df}=1.96, \mathrm{CFI}=0.52, \mathrm{GFI}=0.70\right.$, TLI $=0.57$, 
and RMSEA = 0.23). Although this test has limitations [57], it at least indicates that one factor does not emerge in this study.

Table 1. Descriptive statistics, correlations, and reliability.

\begin{tabular}{ccccccc}
\hline Variable & Mean & SD & $\mathbf{1}$ & $\mathbf{2}$ & $\mathbf{3}$ & $\mathbf{4}$ \\
\hline 1. EI & 4.12 & 1.02 & $(0.82)$ & & & \\
2. Motivation & 4.96 & 0.73 & $0.21^{* *}$ & $(0.81)$ & & \\
3. JE & 4.48 & 1.00 & $0.30^{* *}$ & $0.51^{* *}$ & $(0.92)$ & \\
4. GNS & 5.62 & 0.89 & 0.06 & $0.43^{* *}$ & $0.45^{* *}$ & $(0.86)$
\end{tabular}

** $p<0.01$. Note: $N=235$. Reliabilities are in parentheses; $\mathrm{EI}=$ economic individualism; JE $=$ job engagement; GNS = growth need strength

To examine Hypotheses $\mathrm{H} 1$ and H2, regression analyses and the PROCESS macro [15] were used. Table 2 presents the results of the regression analyses. Model 1 first showed that economic individualism has a significant relationship with work motivation $(\beta=0.24$, $p<0.01)$. Next, Model 2 showed that economic individualism has a significant relationship with job engagement $(\beta=0.31, p<0.01)$. In Model 3 , work motivation was added to economic individualism. Work motivation was a significant predictor $(\beta=0.48, p<0.01)$ and the effect of economic individualism on job engagement dropped from 0.31 to 0.19 . The PROCESS macro uses bootstrapping to examine indirect effects because bootstrapping resolves the problem of nonnormality violations [58,59]. These results indicated that work motivation plays a mediating role, as the indirect effect was 0.10 and the bootstrap confidence interval (CI) did not contain zero $(95 \%$ CI $(0.01,0.19))$. Thus, Hypotheses H1 and $\mathrm{H} 2$ were supported.

Table 2. Mediating effect of work motivation in the relationship between economic individualism and job engagement.

\begin{tabular}{|c|c|c|c|c|c|c|}
\hline \multirow{3}{*}{ Variable } & \multirow{2}{*}{\multicolumn{2}{|c|}{$\frac{\text { Model } 1}{\text { Motivation }}$}} & \multicolumn{2}{|c|}{ Model 2} & \multicolumn{2}{|c|}{ Model 3} \\
\hline & & & \multicolumn{2}{|c|}{ JE } & \multicolumn{2}{|c|}{$\mathrm{JE}$} \\
\hline & $\beta$ & $t$ & $\beta$ & $t$ & $\beta$ & $t$ \\
\hline \multicolumn{7}{|l|}{ Control variables } \\
\hline Gender & 0.00 & 0.05 & 0.04 & 0.52 & 0.03 & 0.56 \\
\hline Age & -0.05 & -0.31 & 0.02 & 0.11 & 0.04 & 0.30 \\
\hline $\begin{array}{l}\text { Occupation } \\
\text { Tenure }\end{array}$ & -0.05 & -0.37 & 0.08 & 0.59 & 0.11 & 0.88 \\
\hline Firm Size & -0.04 & -0.54 & 0.06 & 0.98 & 0.08 & 1.43 \\
\hline \multicolumn{7}{|l|}{ Independent variable } \\
\hline EI & 0.24 & $3.57^{* *}$ & 0.31 & $4.70 * *$ & 0.19 & $3.28 * *$ \\
\hline \multicolumn{7}{|l|}{ Mediator } \\
\hline Motivation & & & & & 0.48 & $8.44^{* *}$ \\
\hline$F$ & \multicolumn{2}{|c|}{$2.77^{*}$} & \multicolumn{2}{|c|}{$6.08^{* *}$} & \multicolumn{2}{|c|}{$18.54^{* *}$} \\
\hline$R^{2}$ & \multicolumn{2}{|c|}{0.06} & \multicolumn{2}{|c|}{0.12} & \multicolumn{2}{|c|}{0.33} \\
\hline Adjusted $R^{2}$ & \multicolumn{2}{|c|}{0.04} & \multicolumn{2}{|c|}{0.10} & \multicolumn{2}{|c|}{0.32} \\
\hline
\end{tabular}

${ }^{*} p<0.05 ;{ }^{* *} p<0.01$. Note: $\mathrm{EI}=$ economic individualism; JE = job engagement.

To examine Hypothesis H3, we used moderated hierarchical regression analysis (see Table 3). In the first step, demographics as control variables were entered. In the second step, economic individualism and GNS were added. In the third step, the interaction between economic individualism and GNS was added (the interaction term was obtained by multiplying the two mean-centered variables). Results revealed no significant interaction between economic individualism and GNS. Thus, Hypothesis H3 was not supported. It should also be noted that we investigated multicollinearity using the variance inflation factor (VIF). In general, a VIF value of less than 10 suggests that multicollinearity is not a major issue [60]. In this study, all VIF values were between 1 and 10, indicating multicollinearity is not a major problem in this research. 
Table 3. Moderating effect of GNS in the relationship between economic individualism and work motivation.

\begin{tabular}{|c|c|c|c|c|c|c|}
\hline \multirow{2}{*}{ Variable } & \multicolumn{2}{|c|}{ Model 1} & \multicolumn{2}{|c|}{ Model 2} & \multicolumn{2}{|c|}{ Model 3} \\
\hline & $\beta$ & $t$ & $\beta$ & $t$ & $\beta$ & $t$ \\
\hline \multicolumn{7}{|l|}{ Control variables } \\
\hline Gender & -0.05 & -0.64 & 0.01 & 0.20 & 0.01 & 0.22 \\
\hline Age & -0.08 & -0.55 & 0.00 & -0.02 & 0.02 & 0.15 \\
\hline $\begin{array}{l}\text { Occupation } \\
\text { Tenure }\end{array}$ & 0.02 & 0.16 & -0.06 & -0.49 & -0.09 & -0.67 \\
\hline Firm Size & -0.03 & -0.45 & -0.10 & -1.68 & -0.11 & -1.78 \\
\hline \multicolumn{7}{|c|}{ Independent variable } \\
\hline EI & & & 0.21 & $3.32 * *$ & 0.20 & $3.14^{* *}$ \\
\hline \multicolumn{7}{|l|}{ Moderator } \\
\hline GNS & & & 0.43 & $7.23 * *$ & 0.43 & $7.21^{* *}$ \\
\hline \multicolumn{7}{|l|}{ Interaction } \\
\hline $\mathrm{EI} \times \mathrm{GNS}$ & & & & & 0.07 & 1.12 \\
\hline$F$ & \multicolumn{2}{|c|}{0.26} & \multicolumn{2}{|c|}{$11.56^{* *}$} & \multicolumn{2}{|c|}{$10.10^{* *}$} \\
\hline$R^{2}$ & \multicolumn{2}{|c|}{0.00} & \multicolumn{2}{|c|}{0.24} & \multicolumn{2}{|c|}{0.24} \\
\hline Adjusted $R^{2}$ & \multirow{2}{*}{\multicolumn{2}{|c|}{-0.01}} & \multicolumn{2}{|c|}{0.22} & \multicolumn{2}{|c|}{0.22} \\
\hline$R^{2}$ Change & & & \multicolumn{2}{|c|}{0.23} & \multicolumn{2}{|c|}{0.00} \\
\hline
\end{tabular}

To examine Hypothesis H4, we again used the PROCESS macro, as this allows for examination of conditional indirect effects. Results are reported in Table 4. At one standard deviation above the mean on our moderator variable (GNS), the conditional indirect effect (0.11) is significant, as the $95 \% \mathrm{CI}$ does not include zero $(95 \% \mathrm{CI}(0.02,0.19))$. In contrast, at the mean and one standard deviation below the mean, the CIs contain zero $(95 \% \mathrm{CI}(-0.01$, $0.17)$ and $(-0.10,0.17)$, respectively). Therefore, Hypothesis H4 was supported.

Table 4. Results for conditional indirect effects.

\begin{tabular}{|c|c|c|c|c|}
\hline Predictor & $B$ & $S E$ & \multicolumn{2}{|c|}{$t$} \\
\hline Constant & 0.52 & 0.40 & \multicolumn{2}{|c|}{1.28} \\
\hline EI & 0.20 & 0.06 & \multicolumn{2}{|c|}{$3.55 * *$} \\
\hline Motivation & 0.64 & 0.08 & \multicolumn{2}{|c|}{$8.32 * *$} \\
\hline Effect of GNS & Indirect Effect & Boot $S E$ & Boot LLCI & Boot ULCI \\
\hline$-1 S D$ & 0.05 & 0.07 & -0.10 & 0.17 \\
\hline $\mathrm{M}$ & 0.08 & 0.05 & -0.01 & 0.17 \\
\hline$+1 \mathrm{SD}$ & $0.11 *$ & 0.04 & 0.02 & 0.19 \\
\hline
\end{tabular}

Finally, we also conducted several additional analyses to separately explore the components of work motivation (intrinsic motivation and extrinsic motivation) and job engagement (vigor, dedication, and absorption). Focusing on work motivation, for Hypothesis $\mathrm{H} 2$, we tested the effects of economic individualism on intrinsic motivation $(\beta=0.25, p<0.01)$ and extrinsic motivation $(\beta=0.13, p=0.06)$. When intrinsic motivation and economic individualism were examined as predictors of job engagement, intrinsic motivation was a significant predictor $(\beta=0.67, p<0.01)$ and the effect of economic individualism dropped from 0.31 to 0.14 . When extrinsic motivation and economic individualism were examined as predictors of job engagement, extrinsic motivation was a significant predictor $(\beta=0.13$, $p<0.05$ ) but the effect of economic individualism only dropped from 0.31 to 0.29 . The indirect effect of economic individualism on job engagement through intrinsic motivation was $0.17(95 \% \mathrm{CI}(0.07,0.28))$ and through extrinsic motivation was $0.01(95 \% \mathrm{CI}(-0.02$, $0.03)$ ). Therefore, extrinsic motivation did not have a significant indirect effect. To exam- 
ine Hypothesis H3, the original procedure was followed, except intrinsic motivation and extrinsic motivation were examined (separately) instead of overall work motivation. The interaction for intrinsic motivation was still nonsignificant, as was the interaction for extrinsic motivation. To examine Hypothesis H4, again the original procedure was followed, except intrinsic motivation and extrinsic motivation were examined (separately) instead of overall work motivation. For the conditional indirect effects (for intrinsic motivation), at one standard deviation above the mean on our moderator variable (GNS), the conditional indirect effect (0.17) is significant, as the $95 \%$ CI does not include zero $(95 \%$ CI $(0.05,0.29))$. In addition, at the mean, the conditional indirect effect (0.16) is also significant (95\% CI $(0.06,0.25))$. In contrast, at one standard deviation below the mean, the conditional indirect effect $(0.14)$ is not significant $(95 \%$ CI $(-0.05,0.30))$. For the conditional indirect effects (for extrinsic motivation), at one standard deviation above the mean, the mean, and one standard deviation below the mean, the conditional indirect effects are not significant $(95 \%$ CI $(-0.01,0.04),(-0.02,0.03)$, and $(-0.01,0.04)$, respectively). Taken together, these findings indicate that the original pattern of results (involving overall work motivation) holds more for intrinsic motivation than for extrinsic motivation.

Focusing on job engagement, we conducted separate analyses for vigor, dedication, and absorption. Results from these analyses were quite similar to those for overall job engagement, and thus the conclusions are the same whether the focus is on components of job engagement or overall job engagement.

\section{Discussion}

This study contributes to the existing body of knowledge on the role played by individuals' broad values on individual outcomes by examining the relationship between economic individualism and job engagement while also exploring the mechanisms underlying this relationship. Specifically, this study investigated a model involving work motivation and GNS. Although previous research has examined antecedents of job engagement [30-33], this work investigated predictors such as job characteristics (e.g., autonomy, task variety, task significance), leadership, and personality traits [26]. The current study extended this research by examining values, specifically economic individualism, as a potential predictor of engagement. To our knowledge, no studies have addressed the potential implications of economic individualism in this context, as prior research on economic individualism has focused on the societal and organizational levels $[7,8]$. Accordingly, the current study changes the level of analysis to examine when and why economic individualism may predict engagement at the individual level.

Results showed that economic individualism is an influential predictor of job engagement within the context of South Korean society. In other words, those who place greater value on individual economic accomplishment experience higher levels of job engagement. Furthermore, the results of the study revealed that work motivation (particularly intrinsic motivation) functions as a mediator between economic individualism and job engagement. Individuals who are high in economic individualism may be more motivated because they believe economic decisions and achievements should be under the individual's control. Finally, results also indicated that the indirect effect through work motivation (specifically intrinsic motivation) holds at higher levels of GNS but not at lower levels. These findings provide new insights regarding the nature of economic individualism, its organizational implications (specifically in terms of engagement), and when and why these implications hold (involving work motivation and GNS). These insights may be useful in further informing practical applications and theoretical models related to employee engagement.

\section{Conclusions}

This study contributes to theory by extending the VAB model. More specifically, the study is significant in that it indicates that the VAB theory can be applied to Korean corporate organizations by confirming that economic individualism as a value affects organizational behavior/attitudes such as job engagement. It is also significant in that it 
reveals that the VAB model, which has been used to explain consumer purchasing behavior, can be applied not only to the marketing field but also to organizational behavior.

From a practical perspective, this research highlights an important predictor in the determination of job engagement and work motivation that has not been examined. Economic individualism was positively related to both job engagement and work motivation. This can help inform selection decisions for those who are interested in increasing job engagement and work motivation. In addition, managers can assess their current employees to see which employees need greater support and direction. For instance, in some circumstances, it may not be as important for managers to focus on those who are high in economic individualism and GNS; instead, the manager might focus more on those who are low in economic individualism and GNS.

This research adds to the literature on job engagement by examining another significant predictor of engagement that has been understudied. Job engagement has been shown to have various important organizational outcomes such as higher organizational commitment and lower turnover intentions [13]. This research adds another predictor to this context that could be integrated into engagement models. In addition, previous research has focused on economic individualism at the national level rather than at the individual level. These national influences are likely to impact individual behavior and attitudes, such as job engagement and work motivation. This expands the domain of economic individualism and applies it to specific organizational settings, which has not been done to date to our knowledge.

\section{Limitations}

The current study is not without limitations. For example, the measures used in this study were self-report, which may be limited by social desirability effects. Note, however, that this research examined constructs that are not easily observable, making alternative measures difficult. Indeed, Chan [61] has argued that the use of self-report measures is not only justifiable but also probably necessary when assessing certain self-referential constructs. Thus, the use of self-report seems reasonable in this study, but future research might attempt to find alternative operationalizations to build on the current findings. In addition, these measures were administered at one time point, making it difficult to draw clear conclusions regarding the direction of relationships. Future studies might attempt to measure these variables at different time points to begin addressing this issue.

This design may also increase the potential for CMV. Given the complexity of CMV, several points are worth noting. First, Spector [62] has argued that the notion that "there is universally shared variance inherent in our methods is both an exaggeration and oversimplification of the true state of affairs" (p. 230). Furthermore, some empirical evidence is broadly consistent with this as findings have indicated that the influence of method effects on the estimation of substantive relationships may be trivial [61]. Second, economic individualism at the individual level is a new issue/phenomenon, and thus the goal of this research examined some foundational relationships as a first step in exploring this construct [63]. The current design is appropriate for this first step and lays the foundation for future research that might extend the current findings with other designs. Third, it has also been argued that more complicated models reduce the likelihood of CMV [64]. The current study involved both mediation and conditional indirect effects, rather than simply bivariate relationships. This argument thus suggests that the more complicated patterns observed in this research may be less likely to reflect CMV.

In addition, the current study focused on economic individualism and did not explore other economic views (e.g., economic collectivism). As noted previously, some research [19] suggests that individualism and collectivism may be separate dimensions, and this could be examined in future research to confirm the multidimensional nature of these variables in the context of economic views and investigate the extent to which they have unique effects. For example, economic individualism may have beneficial motivational implications in certain organizational systems (e.g., where rewards are based on individual achievement), 
whereas economic collectivism may have advantages in other systems (e.g., where rewards are applied uniformly regardless of individual achievement).

Author Contributions: Conceptualization, J.S.; formal analysis, N.A.M. and J.C.; methodology, P.D.C. and O.P.; project administration, K.Y.; written, J.S., N.A.M., J.C., P.D.C., O.P. and K.Y. All authors have read and agreed to the published version of the manuscript.

Funding: This research received no external funding.

Institutional Review Board Statement: Not applicable.

Informed Consent Statement: Informed consent was obtained from all subjects involved in the study.

Data Availability Statement: Data presented in this manuscript are available upon request from the corresponding author.

Conflicts of Interest: The authors declare no conflict of interest.

\section{References}

1. Locke, E.A. The nature and causes of job satisfaction. In Handbook of Industrial and Organizational Psychology; Dunnette, M.D., Ed.; Rand McNally College Publishing Company: Chicago, IL, USA, 1976.

2. O'Reilly, C.A.; Chatman, J.; Caldwell, D.F. People and organizational culture: A profile comparison approach to assessing person-organization fit. Acad. J. Manag. 1991, 34, 487-516.

3. Guiso, L.; Sapienza, P.; Zingales, L. People's opium? Religion and economic attitudes. J. Monet. Econ. 2003, 50, 225-282. [CrossRef]

4. Arikan, G.; Ben-Nun Bloom, P. The influence of societal values on attitudes towards immigration. Int. Political Sci. Rev. 2013, 34, 210-226. [CrossRef]

5. Hofstede, G.; Bond, M.H. The Confucius connection: From cultural roots to economic growth. Organ. Dyn. 1988, 16, 5-21. [CrossRef]

6. Arikan, G. Economic Individualism and Cross-National Differences in Redistribution. Ph.D. Thesis, Stony Brook University, Stony Brook, NY, USA, 2010.

7. Hasenfeld, Y.; Rafferty, J.A. The Determinants of Public Attitudes Toward the Welfare State. Soc. Forces 1989, 67, 1027-1048. [CrossRef]

8. Shen, F.; Edwards, H.H. Economic individualism, humanitarianism, and welfare reform: A value-based account of framing effects. J. Commun. 2005, 55, 795-809. [CrossRef]

9. Steele, L.G.; Lynch, S.M. The pursuit of happiness in China: Individualism, collectivism, and subjective well-being during China's economic and social transformation. Soc. Indic. Res. 2013, 114, 441-451. [CrossRef]

10. Dowling, J.; Pfeffer, J. Organizational legitimacy: Social values and organizational behavior. Pac. Sociol. Rev. 1975, 18, 122-136. [CrossRef]

11. Thompson, D.W.; Panwar, R.; Hansen, E.N. Examining social responsibility orientation gaps between society and industry executives. Manag. Decis. 2010, 48, 156-171. [CrossRef]

12. Oyserman, D.; Coon, H.M.; Kemmelmeier, M. Rethinking individualism and collectivism: Evaluation of theoretical assumptions and meta-analyses. Psychol. Bull. 2002, 128, 3-72. [CrossRef]

13. Bhatnagar, J.; Biswas, S. Predictors \& outcomes of employee engagement: Implications for the resource-based view perspective. Indian J. Ind. Relat. 2010, 46, 273-286.

14. Gierveld, J.H.; Bakker, A.B. The Influence of the Secretary; Manpower: Diemen, The Netherlands, 2005.

15. Hayes, A.F. Introduction to Mediation, Moderation, and Conditional Process Analysis: A Regression-Based Approach, 1st ed.; The Guilford Press: New York, NY, USA, 2013.

16. Gorodnichenko, Y.; Roland, G. Which dimensions of culture matter for long-run growth? Am. Econ. Rev. 2011, 101, 492-498. [CrossRef]

17. Chou, S.A. Individualism and Civic Engagement; The University of Nebraska-Lincoln: Lincoln, NE, USA, 2008.

18. Feldman, S. Structure and consistency in public opinion: The role of core beliefs and values. Am. J. Political Sci. 1988, 32, 416-440. [CrossRef]

19. Cozma, I. How are individualism and collectivism measured. Rom. J. Appl. Psychol. 2011, 13, 11-17.

20. Homer, P.M.; Kahle, L.R. A structural equation test of the value-attitude-behavior hierarchy. J. Personal. Soc. Psychol. 1988, 54, 638-646. [CrossRef]

21. Feagin, J. Subordinating the Poor; Prentice: Englewood Cliffs, NJ, USA, 1975.

22. Fong, T.C.T.; Ng, S.M. Measuring engagement at work: Validation of the Chinese version of the Utrecht Work Engagement Scale. Int. J. Behav. Med. 2012, 19, 391-397. [CrossRef]

23. Kluegel, R.; Smith, R. Beliefs about Inequality: Americans' Views of What Is and What Ought to Be; Routledge: Piscataway, NJ, USA, 1986.

24. Golding, P.; Middleton, S. Images of Welfare: Press and Public Attitudes to Poverty; Robertson: Oxford, UK, 1982. 
25. Schaufeli, W.B.; Salanova, M.; Gonzalez-Romá, V.; Bakker, A.B. The measurement of engagement and burnout: A confirmative analytic approach. J. Happiness Stud. 2002, 3, 71-92. [CrossRef]

26. Christian, M.S.; Garza, A.S.; Slaughter, J.E. Work engagement: A quantitative review and test of its relations with task and contextual performance. Pers. Psychol. 2011, 64, 89-136. [CrossRef]

27. Ashforth, B.E.; Humphrey, R.H. Emotion in the workplace: A reappraisal. Hum. Relat. 1995, 48, 97-125. [CrossRef]

28. Hochschild, A. Feeling management: From private to commercial uses. In The Managed Heart; University of California Press: Berkeley, CA, USA, 2012. [CrossRef]

29. Bakker, A.B.; Demerouti, E.; Verbeke, W. Using the job demands-resource model to predict burnout and performance. Hum. Resour. Manag. 2004, 43, 83-104. [CrossRef]

30. Demerouti, E.; Bakker, A.B.; Nachreiner, F.; Schaufeli, W.B. The job demands-resources model of burnout. J. Appl. Psychol. 2001, 86, 499-512. [CrossRef] [PubMed]

31. Mauno, S.; Kinnunen, U.; Ruokolainen, M. Job demands and resources as antecedents of work engagement: A longitudinal study. J. Vocat. Behav. 2007, 70, 149-171. [CrossRef]

32. Saks, A.M. Antecedents and consequences of employee engagement. J. Manag. Psychol. 2006, 21, 600-619. [CrossRef]

33. Xanthopoulou, D.; Bakker, A.B.; Demerouti, E.; Schaufeli, W.B. The role of personal resources in the job demands-resources model Int. J. Stress Manag. 2007, 14, 121-141. [CrossRef]

34. De Lange, A.H.; De Witte, H.; Notelaers, G. Should I stay or should I go? Examining longitudinal relations among job resources and work engagement for stayers versus movers. Work Stress 2008, 22, 201-223. [CrossRef]

35. Xanthopoulou, D.; Baker, A.B.; Heuven, E.; Demerouti, E.; Schaufeli, W.B. Working in the sky: A diary study on work engagement among flight attendants. J. Occup. Health Psychol. 2008, 13, 345-356. [CrossRef]

36. Schaufeli, W.B.; Bakker, A.B. Job demands, job resources, and their relationship with burnout and engagement: A multi-sample study. J. Organ. Behav. 2004, 25, 293-315. [CrossRef]

37. Milfont, T.L.; Duckitt, J.; Wagner, C. A cross-cultural test of the value-attitude-behavior hierarchy. J. Appl. Soc. Psychol. 2010, 40, 2791-2813. [CrossRef]

38. Diefendorff, J.M.; Chandler, M.M. Motivating employees. In APA Handbooks in Psychology. APA Handbook of Industrial and Organizational Psychology, Vol. 3. Maintaining, Expanding, and Contracting the Organization; Zedeck, S., Ed.; APA: Washington, DC, USA, 2011; pp. 65-135.

39. Deci, E.L.; Olafsen, A.H.; Ryan, R.M. Self-determination theory in work organizations: The state of a science. Annu. Rev. Organ. Psychol. Organ. Behav. 2017, 4, 19-43. [CrossRef]

40. Deci, E.L.; Ryan, R.M. Self-determination theory and the facilitation of intrinsic motivation, social development, and well-being. Am. Psychol. 2000, 55, 68-78.

41. Van Herpen, M.; Van Praag, M.; Cools, K. The effects of performance measurement and compensation on motivation: An empirical study. Economist 2005, 153, 303-329. [CrossRef]

42. Khan, W.; Iqbal, Y. An Investigation of the Relationship between Work Motivation (Intrinsic \& Extrinsic) and Employee Engagement: A Study on Allied Bank of Pakistan. 2013. Available online: http://www.diva-portal.org/smash/get/diva2: 709127/FULLTEXT03.pdf (accessed on 3 December 2021).

43. Van den Broeck, A.; Vansteenkiste, M.; De Witte, H.; Lens, W. Explaining the relationships between job characteristics, burnout, and engagement: The role of basic psychological need satisfaction. Work Stress 2008, 22, 277-294. [CrossRef]

44. Shalley, C.E.; Gilson, L.L.; Blum, T.C. Interactive effects of growth need strength, work context, and job complexity on self-report creative performance. Acad. Manag. J. 2009, 52, 489-505. [CrossRef]

45. Hackman, J.R.; Oldham, G.R. Work Redesign; Addison-Wesley: Boston, MA, USA, 1980.

46. Das, B. Individual growth need strength as a moderator of the relationship of worker satisfaction and job attitudes to worker productivity. J. Hum. Ergol. 1991, 20, 89-94.

47. Oldham, G.R.; Fried, Y. Job design research and theory: Past, present and future. Organ. Behav. Hum. Decis. Process. 2016, 136, 20-35. [CrossRef]

48. Oldham, G.R.; Hackman, J.R. Not what it was and not what it will be: The future of job design research. J. Organ. Behav. 2010, 31, 463-479. [CrossRef]

49. Hackman, J.R.; Oldham, G.R. Development of the Job Diagnostic Survey. J. Appl. Psychol. 1975, 60, 159-170. [CrossRef]

50. Zargar, M.S.; Vandenberghe, C.; Marchand, C.; Ayed, A.K.B. Job scope, affective commitment, and turnover: The moderating role of growth need strength. J. Occup. Organ. Psychol. 2014, 87, 280-302. [CrossRef]

51. Brislin, R.W. Translation and content analysis of oral and written materials. Methodology 1980, 2, 389-444.

52. Breevaart, K.; Bakker, A.B.; Demerouti, E.; Hetland, J. The measurement of state work engagement. Eur. J. Psychol. Assess. 2012, 28, 305-312. [CrossRef]

53. Hallberg, U.E.; Schaufeli, W.B. Same same but different? Can work engagement be discriminated from job involvement and organizational commitment? Eur. Psychol. 2006, 11, 119. [CrossRef]

54. Schaufeli, W.B.; Bakker, A.B.; Salanova, M. The measurement of work engagement with a short questionnaire: A cross-national study. Educ. Psychol. Meas. 2006, 66, 701-716. [CrossRef]

55. Güngör, P. The relationship between reward management system and employee performance with the mediating role of motivation: A quantitative study on global banks. Procedia Soc. Behav. Sci. 2011, 24, 1510-1520. [CrossRef] 
56. Brannick, M.T.; Chan, D.; Conway, J.M.; Lance, C.E.; Spector, P.E. What is method variance and how can we cope with it? A panel discussion. Organ. Res. Methods 2010, 13, 407-420. [CrossRef]

57. Podsakoff, P.M.; MacKenzie, S.B.; Lee, J.Y.; Podsakoff, N.P. Common method biases in behavioral research: A critical review of the literature and recommended remedies. J. Appl. Psychol. 2003, 885, 10-1037. [CrossRef]

58. Hayes, A.F. Beyond Baron and Kenny: Statistical mediation analysis in the new millennium. Commun. Monogr. 2009, 76, 408-420. [CrossRef]

59. Preacher, K.J.; Hayes, A.F. Contemporary approaches to assessing mediation in communication research. In The Sage sourceBook of Advanced Data Analysis Methods for Communication Research; Hayes, A.F., Slater, M.D., Snyder, L.B., Eds.; Sage Publications: Thousand Oaks, CA, USA, 2008; pp. 13-54.

60. Hair, J.F., Jr.; Anderson, R.E.; Tatham, R.L.; Black, W.C. Multivariate Data Analysis, 3rd ed.; Macmillan Publishing Company: New York, NY, USA, 1995.

61. Chan, D. Method effects of positive affectivity, negative affectivity, and impression management in self-reports of work attitudes. Hum. Perform. 2001, 14, 77-96. [CrossRef]

62. Spector, P.E. Method variance in organizational research: Truth or urban legend? Organ. Res. Methods 2006, 9, 221-232. [CrossRef]

63. Spector, P.E. Do not cross me: Optimizing the use of cross-sectional designs. J. Bus. Psychol. 2019, 34, 125-137. [CrossRef]

64. Chang, S.J.; Van Witteloostuijn, A.; Eden, L. From the editors: Common method variance in international business research. J. Int. Bus. Stud. 2010, 41, 178-184. [CrossRef] 